\title{
Mapping by VESGEN of Leaf Venation Patterning in Arabidopsis thaliana with Bioinformatic Dimensions of Gene Expression
}

\author{
Patricia Parsons-Wingerter ${ }^{1 *}$, Mary B. Vickerman ${ }^{2}$, Anna-Lisa Paul ${ }^{3}$, and Robert J. Ferl ${ }^{3,4}$ \\ ${ }^{1}$ Ames Research Center, National Aeronautics and Space Administration (NASA), Moffett Field, CA 94035- \\ 1000; ${ }^{2}$ John H Glenn Research Center, National Aeronautics and Space Administration (NASA), Cleveland, OH \\ 44135; ${ }^{3}$ Department of Horticultural Sciences, Program in Plant Molecular and Cellular Biology, University of \\ Florida, Gainesville, FL 32611; ${ }^{4}$ Interdisciplinary Center for Biotechnology, University of Florida, Gainesville, FL \\ 32610
}

\begin{abstract}
The leaf venation of angiosperms is key to their terrestirial dominance. These higher land plants include maple, corn, and ISS model organism Arabidopsis thaliana. The venationdependent photosynthetic capacity of angiosperm leaves is largely responsible for terrestrial production of glucose and atmospheric oxygen, and may be fundamentally important to long-term space colonization. Leaf studies in orbit, where human-tended experiments are limited, can be enhanced by quantifying complex venation patterning. VESsel GENeration Analysis (VESGEN), a beta-level NASA software that analyzes vertebrate and human vascular branching for biomedical applications, is therefore being modified to map the branching venation patterns of dicot angiosperm leaves. By physiological branching rules, VESGEN decomposes a continuously connected vascular tree into its
\end{abstract}

Key words: Angiosperm; Dicot; Dicotyledon; VESsel GENeration Analysis; ISS; Dendritic; Reticulate; Reticular; ARF; Auxin; Adult Leaf; Juvenile Leaf; Vascular Network; Vascular Lattice; Vascular Connectivity

Correspondence to: Patricia Parsons-Wingerter NASA Ames Research Center MS N236-7

Moffett Field, CA 94035-1000

Telephone: 650-604-1729

E-mail: Patricia.A.Parsons-Wingerter@nasa.gov structural (dendritic) branching and reticulate (networked) capillary components.

For an arabidopsis juvenile leaf flown on NASA Space Shuttle Mission (STS)-130, the venation patterning of larger structural vessel orders $1^{\circ}-2^{\circ}$ remained relatively constant compared to normal gravity (by vessel number density $N_{v}, 1.24 \mathrm{E}-5 /$ micron $^{2}$, and $1.29 \mathrm{E}-$ $5 /$ micron $^{2}$, respectively). However, as a measure of increased venation maturity, $N_{v}$ of smaller reticulate orders $\geq 3^{\circ}$ increased considerably from $7.7 \mathrm{E}-6 /$ micron $^{2}$ in ground control to $1.74 \mathrm{E}-$ $5 /$ micron $^{2}$ in the STS-130 leaf. Vascular geometric complexity is another feature of plant development that is governed in part by changes in gene expression patterns responding to environmental influence. We therefore propose that the mapping of leaf venation patterns by VESGEN can provide additional insight into plant responses to the spaceflight environment.

\section{INTRODUCTION}

One fundamental requirement shared by higher terrestrial plants with humans and vertebrate animals is a complex, fractally branching vascular system (Guyton and Hall, 2006; Roth-Nebelsick et al., 2001). Such vasculatures respond with sensitivity to varying physiological needs by modulating the gene expression patterns of morphologically based vascular functions such as fluid, metabolic, and immune factor exchange. Indeed, the midCretaceous phylogenetic explosion in terrestrial 
biodiversity has been attributed recently to the increased density and complexity of angiosperm leaf venation responding to elevated levels of $\mathrm{CO}_{2}$ (Boyce et al., 2009; Brodribb and Feild, 2010; de Boer et al., 2012; Pennisi, 2010). Results of these studies suggest that greater venation within angiosperm leaves optimized the rates of vasculardependent transpiration and photosynthesis, resulting in the sudden increase of other dependent taxa such as pollinators and early mammals.

The importance of leaf venation in angiosperm evolution and development has inspired decades of research and characterizations of leaf vein architecture, ranging from classic morphological studies to the application of modern molecular tools to understand the processes that contributes to vascular patterning (e.g., Candela et al., 1999; Hickey, 1979; Nicotra et al., 2011; Turner and Sieburth, 2003). The complexity of leaf venation can be seen in a maple leaf (Acer argutum, Ellis et al., 2009; Figure 1). Maples display the species-specific branching patterns characteristic of dicots, an angiosperm group that includes the model plant Arabidopsis thaliana (arabidopsis).

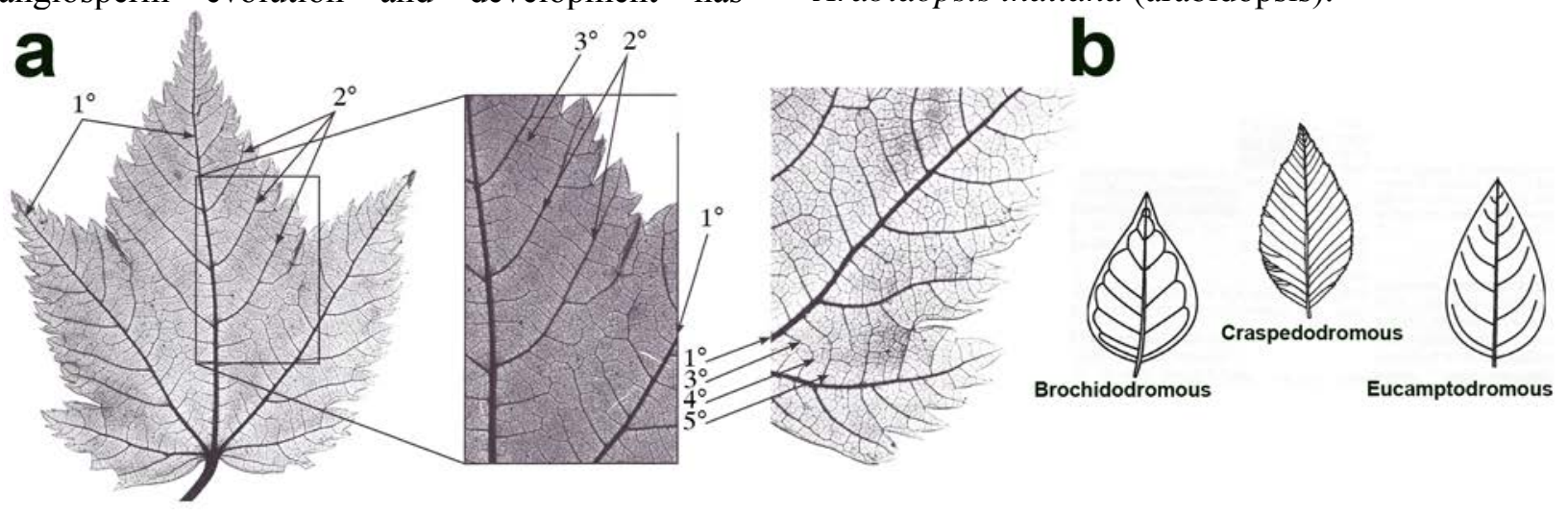

Figure 1. Botanical rules for venation patterning by branching order in higher leaves. Large structural (dendritic) veins of primary $\left(1^{\circ}\right)$ and secondary $\left(2^{\circ}\right)$ branching orders in a dicot angiosperm leaf, such as Acer argutum, are organized as a dendritic tree in which $1^{\circ}$ veins extend from the leaf's base to tip (apex), and $2^{\circ}$ costal (ribbed) veins branch laterally as parallel offshoots from the $1^{\circ}$ vein(s). Cleared leaf images are reproduced from Ellis et al. (2009). Structural veins tend to taper progressively. The reticulate network of orders tertiary and greater $\left(\geq 3^{\circ}\right)$ is composed of smaller, intercostal, connected veins, including end veinlets that terminate at pores where photosynthesis occurs. The vascular dendritic tree connects continuously with the reticulate network to form a unique leaf venation pattern that for angiosperms, is an accepted species taxonomic identifier. Acer argutum is classified as a palmate dicot leaf because of its multiple $1^{\circ}$ veins. (b) For pinnate dicot leaves represented by the three leaf schematics (reproduced from (Roth-Nebelsick et al., 2001)) that include ISS model organism Arabidopsis thaliana (Figures 2-4), $2^{\circ}$ veins branch from a single $1^{\circ}$ vein. Arabidopsis juvenile leaves display brochidodromous leaf venation, whereas adult leaves are semicraspedodromous (Kang and Dengler, 2004). Overall, venation patterns in angiosperm leaves are organized as tree-network composites.

As well characterized as leaf venation has been, there is a recognized need for improved, automated quantification of leaf venation patterning (Ellis et al., 2009; Roth-Nebelsick et al., 2001). It is this need that we address in the current study with the VESsel GENeration Analysis (VESGEN) software, where quantification and automation would enhance the success of the experiment. Moreover, as an insightful research discovery tool, VESGEN helps to define and understand the physiological and anatomical effects of changes in complex molecular signaling. Significant, novel discoveries made with VESGEN in normal and pathological microvascular remodeling for human and vertebrate development and disease include the multimodal morphological effects of the cytokine, vascular endothelial growth factor (VEGF) (Parsons-Wingerter et al., 2006a), and the surprisingly regenerative, early-stage progression 
of a blinding human retinal disease (ParsonsWingerter et al., 2010).

Plants have a long history in spaceflight research (Ferl et al., 2002; Paul et al., 2013a; Wolverton and Kiss, 2009). In orbital studies to date, leaves have been characterized primarily for photosynthetic function and chemical composition, which can be enhanced or diminished in microgravity (Levine, 2010; Monje et al., 2005; Monje et al., 2006; Musgrave, 2007; Tripathy et al., 1996). An aspect of leaf morphology that has yet to be explored in spaceflight material is the pattern of venation in leaves as they develop on orbit. A developmental approach that has been explored in numerous ground studies is the comparison of how venation patterns change in leaves of developmental stages. Sometimes referred to as "juvenile", the first few true leaves of arabidopsis are relatively small, have little or no serrations, lack abaxial trichomes, and possess simpler venation patterns than leaves that develop later. The arabidopsis juvenile phase can be further subdivided into the younger V1 and slightly older V2 phases (Chua et al., 2005; Clarke et al., 1999; Kang and Dengler, 2004; Kankel et al., 2003; Telfer et al., 1997; Willmann and Poethig, 2011).

As a typical example, several juvenile leaves emerge first in arabidopsis (Figure 2; Kang and Dengler, 2004). Once juvenile leaves are fully expanded, their characteristics persist throughout their existence, thereby providing a distinctive snapshot of the developmental changes associated with the juvenile-to-adult leaf progressive growth sequence termed "vegetative phase change" (Poethig, 1990; Pulido and Laufs, 2010; Scarpella and Helariutta, 2010; Wu et al., 2009). The more numerous, larger adult arabidopsis leaves emerge later, expand and mature with much more complex venation patterning. In addition to the development of trichomes on both abaxial and adaxial surfaces, they also generally have greater rates of photosynthesis (Bauer and Thoni, 1988; Huijser and Schmid, 2011; Velikova et al., 2008).


Figure 2. Arabidopsis as model organism of leaf venation patterning in dicot angiosperms. Illustrations of the adult plant by (a) watercolor with roots (Sturm, 1796) and (b) photograph (Page and Grossniklaus, 2002). (c) Rosette stage of young juvenile and adult leaves (Paul et al., 2001). (d) Graph reproduced from Kang and Dengler (2004) quantifies the developmental time course of expansion for the Arabidopsis leaf lamina and petiole of juvenile Leaf 1 and adult Leaf 8. (e) Arabidopsis seedlings cultivated within NASA's Advanced Biological Research System (ABRS, see Paul et al., 2012; Paul et al., 2013b). 
The VESGEN software was developed by NASA as a complex plug-in to the image processing software ImageJ (National Institutes of Health, US) to analyze normal and pathological vascular remodeling and therapeutic interventions for vertebrate systems such as human vessels in clinical images. The software algorithms are based on physiological rules for vascular branching and blood flow (Parsons-Wingerter et al., 2010; Parsons-Wingerter and Reinecker, 2012 ; Vickerman et al., 2009). We are now adapting VESGEN to map and quantify dicot leaf venation patterning for ISS and terrestrial applications using the same physiological rulesbased strategy. Branching rules for dicot leaf venation and vertebrate vessels are both similar and different (Guyton and Hall, 2006; ParsonsWingerter et al., 2010; Vogel, 2012). For example, the fractal-based, branching vascular systems of both dicot leaves and vertebrates are regulated by homeobox gene, hormonal and cytokine signaling (Horowitz and Simons, 2009; Lamont and Childs, 2006; Scarpella and Helariutta, 2010), and vessel branching is essentially bifurcational (Bassingthwaighte et al., 1994; Ellis et al., 2009). Most vascular systems are composed of large structural branching vessels (dendrites or trees) that transport metabolic and immune substances to and from smaller capillary reticulate networks that directly support individual cells within an organ or tissue such as a leaf. Meaningful quantification of microvascular remodeling therefore requires measurements of site-specific changes within vascular trees and networks because the averaging of vessel diameter and other vascular parameters over many successively smaller, morphologically and functionally diverse branching generations does not yield particularly useful, informative results.

Unlike the vertebrate arteriovenous circulation that is driven by a cardiac pump, the plant vasculature consists of a single branching venous system for which the gravitational, osmotic and other governing forces driving vascular flow are not yet fully understood (Taiz and Zeiger, 2010). The dense, reticulated leaf venation patterns of dicots branch sequentially to terminate as an open veinlet at each stomatic pore, where the veinlet participates in photosynthesis by delivering water and removing glucose (de Boer et al., 2012). Dicots are now the dominant plants on Earth in both number and prevalence of species (Crepet and Niklas, 2009; Parsons-Wingerter et al., 2010; Pennisi, 2010). Clearly, dicot leaf venation is important for both terrestrial life and the successful adaptation of plants to future space exploration and colonization.

VESGEN therefore represents a coalescence of vascular pattern recognition analysis across biological kingdoms by utilizing both commonalities and differences in vascular patterning in biology, especially as applied to the space life sciences context. Numerous other computer softwares currently available for imaging pattern analysis in plant tissues and organs include root and cellular morphology, leaf area, and some vascular patterning features (Lobet, 2013-2014; Price et al., 2011; RollandLagan et al., 2009). The unique, innovative contribution of VESGEN derives from our design strategy that uses vascular physiological branching rules to first determine (map) the vessel branching orders (generations), and then quantify site-specific changes in the vascular pattern in response to developmental, environmental, evolutionary, and pathological stimuli.

\section{METHODS}

\section{Arabidopsis Culture and Experiments}

A spaceflight-grown juvenile arabidopsis Leaf 2 was obtained from one of the plants on NASA shuttle mission STS-130 as part of the APEXTAGES flight experiment. The seeds were launched dormant, germinated on nutrient phytagel plates on orbit, and grew for 12 days under 24 hour lighting in the ABRS (Advanced Biological Research System) orbital growth chamber. The plants were harvested and fixed in RNAlater (Ambion) on orbit 12 days after activation of the dormant seed by exposure to light (Ferl et al., 2011; Paul et al., 2012; Paul et al., 2013b). Details of ABRS growth conditions and APEX-TAGES experiment can be found in Paul et al., 2012 and Paul et al., 2013b. Images of the leaf lamina and vasculature for the flight plant and comparable ground control were captured in white light with darkfield background on a Olympus S2X12 fluorescent dissecting microscope coupled to an Evolution MP cooled charge-coupled device camera with Q-capture 2.60 software (Quantitative Imaging, Burnaby, British Columbia, Canada; Figure 3). 

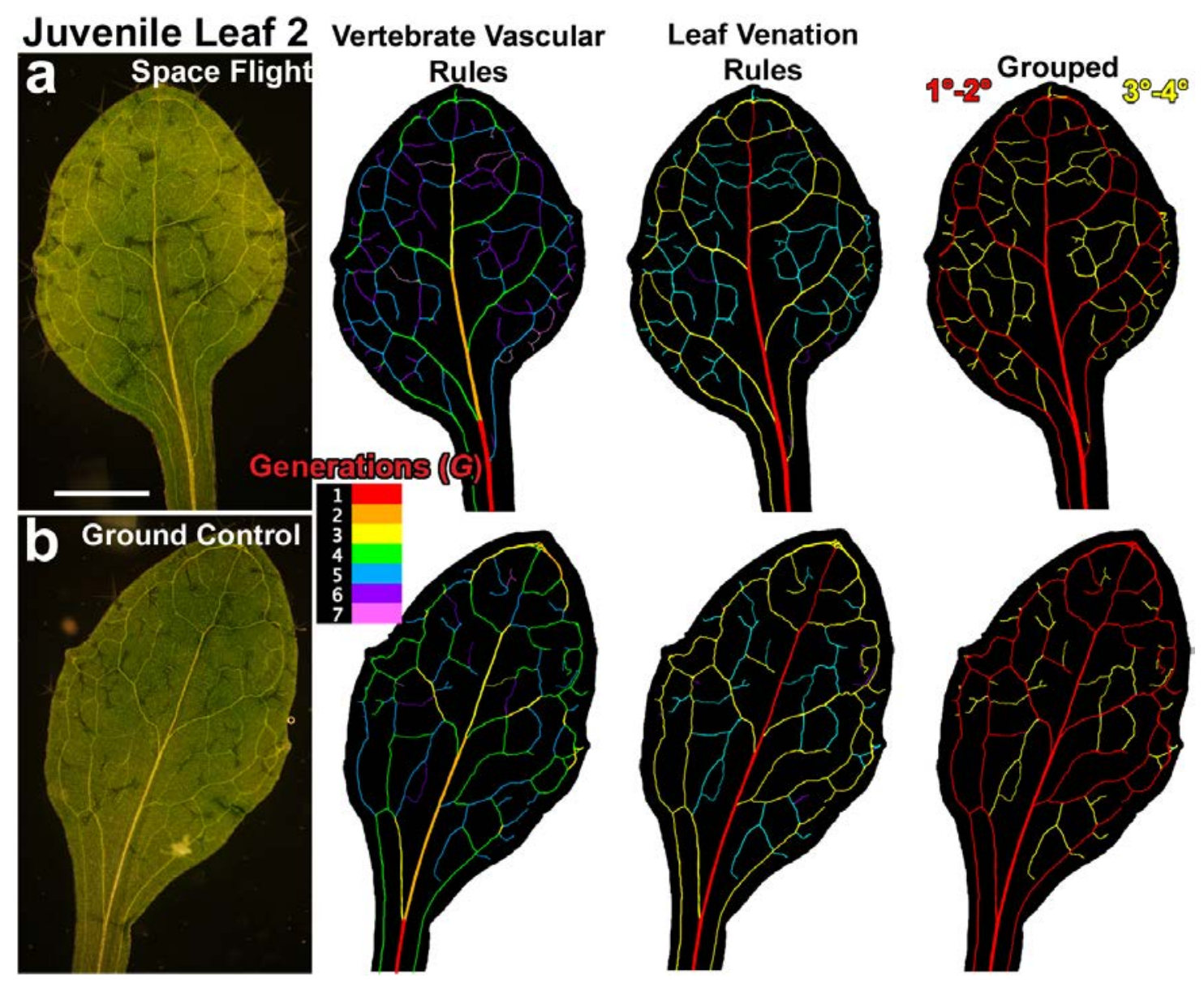

Figure 3. Rules-based mapping of environmental effects on venation patterning that are fundamental to photosynthetic function. (a, b) Arabidopsis juvenile Leaf 2 cultured in the ISS microgravity environment from a spaceflight experiment flown on NASA STS-130 is compared to wild-type ground control. When analyzed by VESGEN according to vertebrate vascular branching rules (second column), the pronounced tapering of vessel diameter in the $1^{\circ}$ midvein resulted in division of the vessel into four segments (Legend: colors corresponding to branching generations $G_{1}-G_{7}$ ). Altering the branching rules according to dicot leaf venation patterning (third column) resulted in successful VESGEN segmentation into venous structural orders $\left(1^{\circ}\right.$, red; $2^{\circ}$, yellow) and reticulate orders $\left(3^{\circ}\right.$, turquoise; $4^{\circ}$, purple). As a second mapping option, vessels were grouped (fourth column) by VESGEN into structural veins $\left(1^{\circ}-2^{\circ}\right)$ and reticulate veins $\left(3^{\circ}-4^{\circ}\right)$. By VESGEN analysis, overall differences between the two juvenile leaves were large for the functionally important smaller (reticulate) veins. $(\mathrm{a}, \mathrm{b}) \mathrm{scalebar}=1 \mathrm{~mm}$.

Adult arabidopsis leaves were not available for analysis from ISS experiments. Consequently, the developmental maturation of remodeling venation was analyzed by comparing images of the adult Leaf 8 at Days 2 and 8 scanned from a study by Kang and Dengler (2004). Juvenile Leaf 2 and adult Leaf 8 were chosen by these authors to investigate progression from the brochidodromous morphology of juvenile leaves (with arching $2^{\circ}$ marginal veins, Figure 1) to the semicraspedodromous adult. The craspedodromous form lacks $2^{\circ}$ marginals, and structural $2^{\circ}$ veins terminate at the leaf margin. An educational timelapse video illustrates sequential juvenile-to-adult leaf sprouting within the arabidopsis rosette (WISTEP, 2014). The venous junvenile-to-adult transformation is associated with patterning changes in the expression of the vascular maturational protein, arabidopsis homeobox-8 (AtHB-8, Figure 4). AtHB-8 (transfected in this study with GUS) is regulated by the phytohormone auxin, a major mediator of molecular signaling pathways that regulate tissue patterning in plant development (Delker et al., 
2008; Scarpella and Helariutta, 2010; Taiz and Zeiger, 2010), as well as ongoing plant metabolism. Kang and Dengler (2004) report that AtHB-8::GUS was expressed completely and permanently throughout the veins of juvenile arabidopsis leaves, but with progressively restricted, highly localized patterning in the veins of growing adult leaves. In the adult Leaf 8 , for example, AtHB-8::GUS was completely expressed in the veins at Day 2, but localized to the basal region at Day 8.
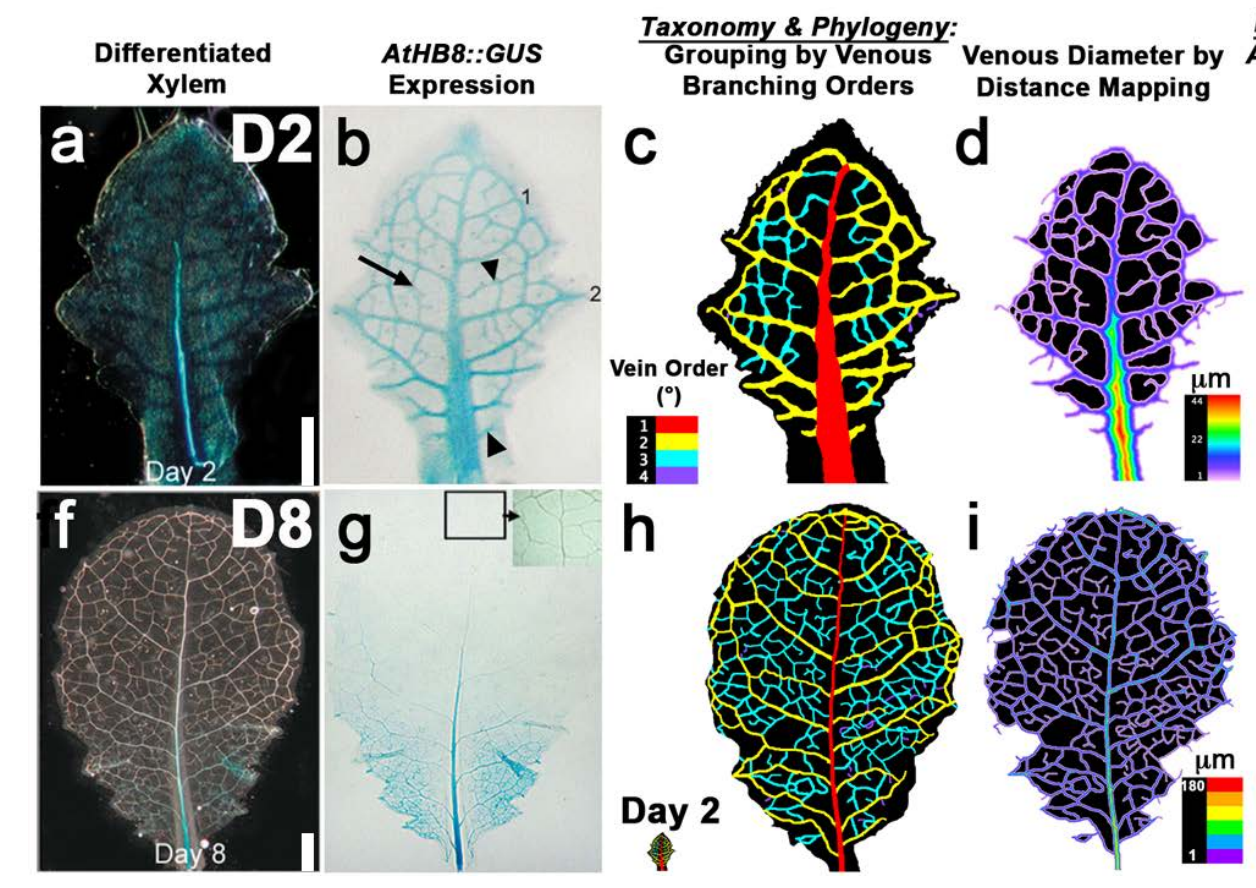

Integrative Bioinformatics: AtHB8::GUS by Structural \& Reticulate Vein Grouping
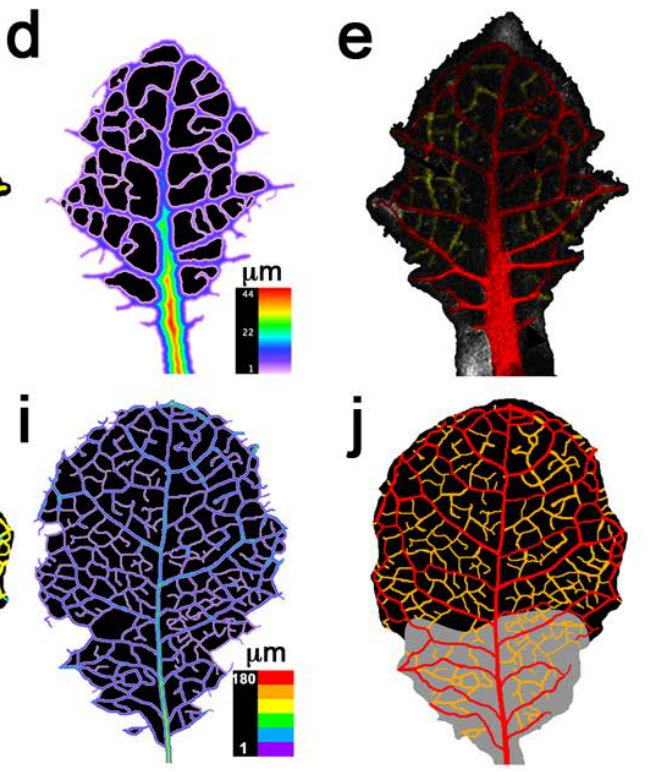

Figure 4. Integrated mapping in arabidopsis of leaf venation pattern with bioinformatic dimension of gene expression by rules-based VESGEN Analysis. Patterns of differentiated xylem (a, f) with AtHB-8::GUS expression $(\mathrm{b}, \mathrm{g})$ in the normally developing arabidopsis adult leaf (Leaf 8) at Day 2 (D2) and Day 8 (D8) of normal development reproduced from a study by Kang and Dengler (2004) were mapped by VESGEN software (c-e, h-j). (c, h) Large structural veins (orders $1^{\circ}$ and $2^{\circ}$ ) and small reticular veins $\left(3^{\circ}\right.$ and $\left.\geq 4^{\circ}\right)$ are mapped with botanical rules summarized in Figure 1. Note the large increase in leaf size and vascular expansion from Day 2 to Day 8 (h). (d, i) Euclidean distance mapping by VESGEN quantifies the local thickness of vessel diameter throughout the vascular tree-network composite. Black indicates enclosed avascular spaces. To demonstrate our proposed VESGEN bioinformatic capability, the time-dependent localized expression of HD-Zip class III transcription factor arabidopsis homeobox gene-8 (AtHB-8::GUS, b, g) was mapped into vascular patterns automatically grouped by VESGEN into structural $\left(1^{\circ}-2^{\circ}\right)$ and reticulate $\left(3^{\circ}-4^{\circ}\right)$ vein orders $(e, j)$. The mapping for Day 2 (e) displays the local intensity of AtHB-8::GUS expression throughout the leaf lamina as a function of the venation architecture and vessel branching order illustrated in panel c. Red intensity levels quantify AtHB-8::GUS expression localized within structural veins of orders $1^{\circ}-2^{\circ}$; yellow intensity levels, within reticulate veins of orders $3^{\circ}-4^{\circ}$; and gray intensity levels, to AtHB-8::GUS expression within the extravascular leaf lamina (intensities brightened for visibility). (j) AtHB8::GUS expression at Day 8 is now restricted to the still-expanding basal region. Quantification corresponding to these mappings for D2 and D8 is summarized in Table 2. CAPTION NOTES from Kang and Dengler (2004): (b) 1, first-formed secondary vein loop; 2 , second-formed secondary vein; black arrowhead, intercalated secondary vein; black arrow, smaller-diameter "connector" joining adjacent secondary vein; (g) inset showing absence of AtHB-8::GUS expression from leaf apex. a, bar $=200 \mu \mathrm{m}$; $\mathrm{f}, \mathrm{bar}=1 \mathrm{~mm}$

\section{VESGEN Mapping and Quantification}

Vascular maps determined automatically by VESGEN provide the basis for subsequent, automated quantification by the software of major vessel parameters that include vessel diameter, fractal dimension, tortuosity, avascular spacing, and densities of vessel area, length, number, and branch point. As a mature beta-level software, 
VESGEN was developed as a sophisticated, userinteractive plug-in to the widely used, freely downloadable software ImageJ in part to support future downloadable public release to the worldwide research community. The biomedical applications, use, and development of the VESGEN software have been reviewed (Vickerman et al., 2009). The vascular treenetwork composite option of VESGEN was used to map and quantify the leaf venation branching patterns. Grayscale images of venation patterns within the leaf lamina were post-processed into black/white (binary) images and then analyzed with the VESGEN tree-network option as described previously.

To begin adapting VESGEN determination of vertebrate vascular branching to leaf venation (Figure 1), experienced users (PP-W and MBV) overrode the automated assignment of branching order (generation) by user-interactive digital reassignment of veins to leaf branching orders according to qualitative rules for many dicot species that are well defined by Ellis and coauthors (2009), who acknowledge their extension of classical studies by K. Esau (1965), L. J. Hickey (1973 and 1979) and others (Figures 1, 34). The major difference between dicot leaf and vertebrate vascular patterning is that leaf structural veins generally (but not always) taper less than vertebrate arteries and veins, presumably due to different physiological requirements for fluid flow compared to cardiac-pumped blood flow. Nonetheless, the physiological branching rules for leaf venation and vertebrate vascular systems share many important patterning features such as bifurcational branching within vascular trees of larger structural vessels to successively smaller vessels of decreasing diameter. In turn, the vascular tree delivers and/or collects fluid with metabolites and other factors to the leaf reticulate and vertebrate capillary networks interacting with local tissue needs.

In summary, the binary image of leaf venation and its region of interest (ROI) were first automatically mapped by VESGEN using the Vascular Tree-Network Composite morphological option to generate the various maps, such as the vascular skeletonized map with vessel branch points and endpoints and the Euclidean distance map. The endpoint of the single pinnate $1^{\circ}$ midvein $\left(1^{\circ}\right.$ structural vein) was digitally reassigned in VESGEN as the primary (first) branching generation. Endpoints of the $2^{\circ}$ costal (ribbed) structural veins and higher order reticulate (networked) veins were evaluated and digitally overridden where appropriate. Within the VESGEN vascular map generated by these endpoints, subregions of interest within a vein were grouped together as the ROI for the midvein and higher-order veins using the wand and ROI tools of ImageJ. The VESGEN user-interactive automated grouping feature was used to group vein branching orders for final summary results (Tables 1-2 and Figures 3-4).

Table 1. Quantification of venation patterning in Arabidopsis Juvenile Leaf 2 by VESGEN analysis. (Large) structural vein orders, $1^{\circ}-2^{\circ} ;\left(\right.$ small) reticulate vein orders, $\geq 3^{\circ}$. Symbols and units: fractal dimension $\left(D_{f}\right)$, unitless (of skeletonized images); vessel area density $\left(A_{v}\right), \mu \mathrm{m}^{2} / \mu \mathrm{m}^{2}$; vessel number density $\left(N_{v}\right), \mu \mathrm{m}^{-2}[$ total number of vessels in leaf lamina $(\mathrm{Nr})]$; vessel diameter $\left(D_{v}\right), \mu \mathrm{m}$.

\begin{tabular}{|c|c|c|c|c|c|c|}
\hline Analysis & Day & $\begin{array}{l}\text { Vessel } \\
\text { Group }\end{array}$ & $D_{f}$ & $A_{v}$ & $\begin{array}{c}N_{v} \\
{[N r]}\end{array}$ & $D_{v}$ \\
\hline Figure 3 & 7 & all orders & 1.34 & 0.0813 & $\begin{array}{c}2.99 \mathrm{E}-5 \\
{[149]}\end{array}$ & - \\
\hline \multirow[t]{2}{*}{$\begin{array}{l}\text { Spaceflight } \\
\text { STS-130 }\end{array}$} & & $1^{\circ}-2^{\circ}$ & - & 0.0569 & $\begin{array}{l}1.24 \mathrm{E}-5 \\
{[62]}\end{array}$ & $1^{\circ}, 19 ; 2^{\circ}, 10$ \\
\hline & & $\geq 3^{\circ}$ & - & 0.0244 & $\begin{array}{l}1.74 \mathrm{E}-5 \\
{[87]}\end{array}$ & $3^{\circ}, 8 ; 4^{\circ}, 7$ \\
\hline \multirow[t]{3}{*}{$\begin{array}{l}\text { Ground } \\
\text { control }\end{array}$} & 7 & all orders & 1.32 & 0.0673 & $\begin{array}{c}2.07 \mathrm{E}-5 \\
{[110]}\end{array}$ & - \\
\hline & & $1^{\circ}-2^{\circ}$ & - & 0.0559 & $\begin{array}{l}1.29 \mathrm{E}-5 \\
{[69]}\end{array}$ & $1^{\circ}, 27 ; 2^{\circ}, 11$ \\
\hline & & $\geq 3^{\circ}$ & - & 0.0120 & $\begin{array}{l}7.70 \mathrm{E}-6 \\
{[41]}\end{array}$ & $3^{\circ}, 8 ; 4^{\circ}, 5$ \\
\hline
\end{tabular}


Table 2. Quantification of venation pattern in Arabidopsis Adult Leaf 8 by VESGEN analysis. (Large) structural vein orders, $1^{\circ}-2^{\circ}$; (small) reticulate vein orders, $\geq 3^{\circ}$. Symbols and units: fractal dimension $\left(D_{f}\right)$, unitless (of skeletonized images); vessel area density $\left(A_{v}\right), \mu \mathrm{m}^{2} / \mu \mathrm{m}^{2}$; vessel number density $\left(N_{v}\right), \mu \mathrm{m}^{-2}$ [total number of vessels in leaf lamina $(\mathrm{Nr})]$; vessel diameter $\left(D_{v}\right), \mu \mathrm{m}$.

\begin{tabular}{|c|c|c|c|c|c|c|}
\hline Analysis & Day & $\begin{array}{l}\text { Vessel } \\
\text { Group }\end{array}$ & $D_{f}$ & $A_{v}$ & $\begin{array}{c}N_{v} \\
{[N r]}\end{array}$ & $D_{v}$ \\
\hline Figure 4 & 2 & all orders & 1.38 & 0.353 & $\begin{array}{c}2.68 \mathrm{E}-4 \\
{[119]}\end{array}$ & - \\
\hline \multirow[t]{5}{*}{ Kang \& Dengler 2004} & & $1^{\circ}-2^{\circ}$ & - & 0.289 & $\begin{array}{c}1.53 \mathrm{E}-4 \\
{[68]}\end{array}$ & $1^{\circ}, 50 ; 2^{\circ}, 17$ \\
\hline & & $\geq 3^{\circ}$ & - & 0.063 & $\begin{array}{c}1.15 \mathrm{E}-4 \\
{[51]}\end{array}$ & $3^{\circ}, 11 ; 4^{\circ}, 8$ \\
\hline & 8 & all orders & 1.47 & 0.298 & $\begin{array}{c}6.2 \mathrm{E}-6 \\
{[411]}\end{array}$ & - \\
\hline & & $1^{\circ}-2^{\circ}$ & - & 0.143 & $\begin{array}{c}2.3 \mathrm{E}-6 \\
{[153]}\end{array}$ & $1^{\circ}, 131 ; 2^{\circ}, 84$ \\
\hline & & $\geq 3^{\circ}$ & - & 0.157 & $\begin{array}{c}3.9 \mathrm{E}-6 \\
{[255]}\end{array}$ & $3^{\circ}, 72 ; 4^{\circ}, 58$ \\
\hline
\end{tabular}

Our plan for future automation of leaf venation analysis is consistent with our previously successful approach to vertebrate VESGEN analysis, in which the semi-automatic Matlab software prototype (Parsons-Wingerter et al., 2006a; Parsons-Wingerter et al., 2000a; ParsonsWingerter et al., 2000b; Parsons-Wingerter et al., $2006 \mathrm{~b}$ ) formed the foundation of subsequently successful software automation (Chen et al., 2013; Liu et al., 2009; McKay et al., 2008; ParsonsWingerter et al., 2010; Parsons-Wingerter and Reinecker, 2012; Vickerman et al., 2009). For this arabidopsis feasibility study, only a single representative leaf was analyzed for each group. Our purpose was to determine rules for accurate, semi-automated mappings that will support future automated analysis prior to large replicate studies. Typical group sizes for statistically significant botanical conclusions on leaf morphology are 5 to 10 (Clay and Nelson, 2005; Kang and Dengler, 2004).

\section{RESULTS}

For the ISS-grown juvenile arabidopsis Leaf 2 , patterning of the larger structural vein orders $1^{\circ}-2^{\circ}$ was essentially equivalent to the terrestrial control grown under normal gravity (Table 1, Figure 3). Vessel number density $\left(N_{v}\right)$, an important vascular complexity parameter, was
1.24E-5 $\mu^{-2}$ for the STS-130 leaf and 1.29E-5 $\mu \mathrm{m}^{-2}$ for ground control. However, increased leaf maturity and greater photosynthetic functional capacity was indicated by the smaller reticulate vein orders $\geq 3^{\circ}$ for the STS-130 leaf, in which $N_{v}$ was $1.29 \mathrm{E}-5 \mu \mathrm{m}^{-2}$ compared to $7.7 \mathrm{E}-6 \mu \mathrm{m}^{-2}$ for the ground control. Whether such a result is representative of arabidopsis leaf development in microgravity environments would clearly require significant statistical replication. However, our results do indicate the suitability of the method for addressing such questions.

Vascular complexity increased during normal terrestrial maturation of adult arabidopsis Leaf 8 (Table 2, Figure 4) by fractal-based measures of venation geometry in association with progressively modulating expression of AtHB8::GUS. By the fractal dimension $\left(D_{f}\right)$, the spacefilling capacity of the leaf vascular pattern increased from 1.38 at Day 2 to 1.47 at Day 8 . The numbers $\left(N_{r}\right)$ of reticulate veins increased from 153 to 255 , respectively, although $N_{r}$ of structural veins decreased from 68 to 51 . The trends of our results are in good agreement with qualitative and quantitative results reported by Kang and Dengler (2004) that included overall measurements of vessel area and counts of vessel branch points and endpoints. However, their vessel quantification did not distinguish between 


\section{VESGEN Mapping of Leaf Venation Patterns in Arabidopsis}

structural and reticulate vascular patterning. Vessel number density $\left(N_{v}\right)$ for structural vessels decreased from $1.53 \mathrm{E}-4 \mu \mathrm{m}^{-2}$ at Day 2 to $2.3 \mathrm{E}-6$ $\mu \mathrm{m}^{-2}$ at Day 8, and for reticulate vessels, from $1.15 \mathrm{E}-4 \mu^{-2}$ to $3.9 \mathrm{E}-6 \mu \mathrm{m}^{-2}$. Results for $N_{v}$ are not in good agreement with those of Kang and Dengler. The Day 8 image, which was scanned from the journal pdf file, is probably of decreased image resolution compared to the original analyzed by Kang and Dengler, which presumably was of sufficient microscopic resolution to resolve all vascular structures. Nonetheless, our results demonstrate the successful semi-automated VESGEN analysis of venation in the mature adult leaf.

At Day 2, the average intensity of our bioinformatic histogram analysis (256 gray levels) for AtHB-8::GUS co-localization with grouped structural orders $\left(1^{\circ}-2^{\circ}\right)$ was $86 \pm 52$ (mean \pm SD), and $40 \pm 20$ with grouped reticulate orders ( $\geq$ $3^{\circ}$ ). Results are confirmed qualitatively by visual inspection of altered expression patterns of AtHB8::GUS (Figure 4). The greater intensity of AtHB8::GUS in structural veins could result from either increased density of expression or from the twodimensional image rendering of larger vessels (or both). We could not map the co-localized expression of AtHB-8::GUS into the veins at Day 8 because the journal image of AtHB-8::GUS localization did not quite overlap with the image of venation patterning. However, to illustrate a second type of useful bioinformatic analysis, the basal location of AtHB-8::GUS expression was successfully estimated and mapped as highly restricted by Day 8 to $29 \%$ of the total vascular area, compared to $100 \%$ at Day 2 .

From the above results, a VESGEN ensemble that combines dimensional parameters of vascular geometry with bioinformatic dimensions of colocalized gene, protein, and other molecular expression can be formulated as:

\section{Equation 1:}

$$
f, \underline{g}=\left\{\left[f_{1, i, \ldots}, f_{2, i, \ldots}, \ldots\right],\left[g_{1, i, \ldots}, g_{2, i, \ldots}, \ldots\right]\right\}
$$

where the vector functions $f$ and $g$ consist of dynamic (i.e., time-dependent), twodimensionally co-localized information. The set $f$ contains parameters of vascular geometry such as $D_{f}$ and $N_{v}$. The vector function $g$ comprises the bioinformatic set of corresponding molecular expression patterns co-localized with the vascular geometry. Results for the adult arabidopsis Leaf 8 at $t=$ Day 2 of development can now be expressed as:

\section{Equation 2:}

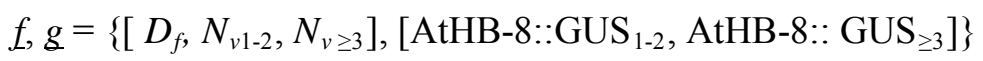

in which $f_{1}=D_{f} ; f_{2,1}=N_{v 1-2}$, the vessel number density in structural veins of orders $1^{\circ}-2^{\circ}$, and $f_{2,2}$ $=N_{v \geq 3}$, vessel number density in reticulate veins of orders $\geq 3^{\circ}$. Many other parameters of vascular morphological complexity such as vessel diameter, length, and densities of branch points and end points can be included in $f$ (for example, see McKay et al., 2008). For co-localized expression of molecular marker AtHB-8::GUS in structural and reticulate veins of orders $1^{\circ}-2^{\circ}$ and $\geq 3^{\circ}, g_{1,1}=$ AtHB-8::GUS ${ }_{1-2}$ and $g_{1,2}=$ AtHB-8:: $\mathrm{GUS}_{\geq 3}$, respectively. Vast numbers of other bioinformatic molecular expression patterns can be combined with vascular geometric information within the VESGEN systems ensemble.

\section{DISCUSSION}

As a methodological feasibility study for space and terrestrial applications, we investigated the physiological rules and methods for mapping and quantification of dicot leaf venation by VESGEN software. Our goals were to: (1) begin applying vascular branching rules of dicot leaf 


\section{VESGEN Mapping of Leaf Venation Patterns in Arabidopsis}

venation to the VESGEN analysis using Abrabidopsis as a first model, (2) assess the similarities and differences of these branching rules compared to vertebrate vascular branching, and (3) perform a semi-automated analysis of several representative juvenile and adult arabidopsis leaves to begin testing and applying the rules. Differences in vascular patterning of a juvenile arabidopsis leaf between spaceflight and ground control (Table 1, Figure 3) and terrestrial maturation in an adult arabidopsis leaf (Table 2, Figure 4) were mapped and quantified. As a further feasibility study, we examined the expression of AtHB8::GUS within the developing adult leaf. Localization of AtHB8::GUS was mapped by VESGEN onto the spatial geometry of hierarchical vascular branching for Day 2 (Table 2, Figure 4).

Previous studies of genetically controlled modifications of leaf venation in development and evolution report basic vascular measures such as overall densities of vessel length and branch points (Boyce et al., 2009; Brodribb and Feild, 2010; Candela et al., 1999; Kang and Dengler, 2004; Kang et al., 2007) and occasionally, vessel diameter and the fractal dimension (RothNebelsick et al., 2001). VESGEN results for hierarchic, site-specific changes within branching vascular trees in humans and vertebrates demonstrate that remodeling vascular patterns serve as informative read-outs that necessarily integrate the interactive signaling of complex signal transduction pathways (Chen et al., 2013; Liu et al., 2009; McKay et al., 2008; ParsonsWingerter et al., 2006a; Parsons-Wingerter et al., 2000a; Parsons-Wingerter et al., 2000b; ParsonsWingerter et al., 2006b; Vickerman et al., 2009; Zamanian-Daryoush et al., 2013). Our goal of fully automating the VESGEN software mapping capabilities for dicot leaf venation patterning includes not only morphological parameters of Euclidean spatial dimensions (the $f$ set, Results), but also the associated bioinformatic dimensions of localized gene, protein, and other types of molecular expression that are essentially infinite in combinatorial number ( $q$ set).

We chose arabidopsis for our first feasibility study of mapping leaf venation patterning because of its central importance in terrestrial and space plant research. Convenient features of this model organism includes its small size $(20-25 \mathrm{~cm})$, short growing period (several weeks), small genome (approximately 25,000 genes), and especially, its distinction as the only plant among the five major genetic model organisms that is readily susceptible to laboratory engineering of targeted single-point mutations (Figure 2; Muller and Grossniklaus, 2010; Taiz and Zeiger, 2010).

Kang and Dengler's comprehensive results (2004) on the scaling of expanding leaf venation in arabidopsis offer important insights. Critical branching complexity parameters, such as densities of vessel branch points and endpoints, appear largely preserved throughout the enormous rescaling of the growing laminar area of Adult Leaf 8 by approximately 100 -fold (i.e., vascular density is highly constant and rescaling is highly invariant). Presumably this density is highly favorable for vascular support of photosynthesis at the stomatic pores. (A similar analysis was not provided for the developing Juvenile Leaf 2 for which branch points were measured, but leaf laminar areas are lacking.) Fractal patterns in biology (Parsons-Wingerter et al., 1998) and mathematics (Mandelbrot, 1983) frequently remain invariant and rescale by preserving their geometric pattern, a mathematical property termed self-similarity. In contrast, Kang and Dengler's results indicate that the venation of the developing adult leaf is not rescaling as a self-similar structure. If this were true, the maturing branching patterns would scale proportionally the distance between the endveinlets, rather than highly preserving their absolute geometric distance or size. Rather, local endveinlet density associated with the stomatic pores appears to be the primary determinant of vascular pattern. In contrast, recent measurements (Dhondt et al., 2012) suggest that venation in the developing arabidopsis Leaf 3 rescales with greater self-similarity. Important questions remain to be resolved about the rescaling of developing and mutated venation patterning in juvenile and especially, adult leaves.

The excellent, comprehensive Plant Image Analysis website (Lobet, 2013-2014) offers 101 softwares that analyze numerous aspects of plant imaging such as cellular phenomena, phylogeny searching, and leaf and root morphology. Several of these computer programs analyze characteristics of leaf venation patterning such as leaf laminar area and areolar extraction. The software capability of quantifying overall vessel 
density in arabidopsis leaves (Rolland-Lagan et al., 2009; Price et al., 2011) are included in the Plant Image Analysis website, and were also reported in our own first, preliminary VESGEN study (Parsons-Wingerter and Vickerman, 2011) that further quantified large (structural) and small (reticulate) vein density. For our new, more advanced VESGEN analysis, up to seven specific branching orders of leaf venation were mapped and quantified (Tables 1-2, Figures 3-4). Results from branching rules for dicot leaf venation were compared to those from vertebrate vascular branching (Figure 3). In addition, the geometric orders of leaf vascular branching were associated for the first time with co-localized mappings of the growth co-factor AtHB-8 as a bioinformatic (information) dimension (Results, Figure 4).

VESGEN and other software analyzing plant morphology can be considered by researchers studying plant development on the ISS with microscopes supported by NASA, the European Space Agency, and the Japanese Aerospace Exploration Agency. For example, the NASA Light Microscopy Module (LMM) that has previously supported colloidal experiments in fluid physics is now being developed for NASA Life Sciences and Space Biology applications (Sicker and Meyer, 2013). Feasibility experiments (STS-134 and 135 payloads) were performed with the LMM to demonstrate imaging of the nematode, fruit fly and other organisms at various conditions of magnification, fluorescence, and live video streaming. Such recent and ongoing experiments will reduce the integration, operations, and experiment development costs of our proposed VESGEN experiments.

The complexity of adult leaf venation patterning in dicot angiosperms, a defining feature of their optimized photosynthetic efficiency, is of enormous functional importance. Perhaps in part because of this system's complexity, venation patterning in adult dicot leaves are understudied on Earth and therefore on the ISS (Ellis et al., 2009; Kang and Dengler, 2004; Roth-Nebelsick et al., 2001). Automating the hierarchical mapping of branching venation pattern would contribute important new capabilities for analyzing leaf adaptations on Earth and in space in applications ranging from fundamental botany to ecology, environmental engineering, and agriculture.

\section{ACKNOWLEDGMENTS}

We thank Fred Kohl and Ron Sicker, NASA GRC, and Krishnan Radhakrishnan, Preventive Medicine and Environmental Health, University of Kentucky, for helpful comments on the manuscript. Arabidopsis culture and microscopy were performed for STS-130 and at the University of Florida by A-LP and RJF, and VESGEN image analysis at NASA by MBV and PPW. The research was supported by NASA Glenn Internal Research \& Development (IR\&D) 04-54, 2010 Technology Transfer and Partnership (TTP) Fund, and 2011 Center Innovation Fund (CIF) Fund to PPW and MBV, NASA Glenn project support for the ISS Light Microscopy Module (LMM) to PPW, and NASA grants NNX07AH27G and NNX09AL96G to RJF and A-LP. NASA, PPW, and MBV have been awarded a provisional US patent application for VESGEN applications to leaf venation and human and vertebrate vasculature.

\section{REFERENCES}

Bassingthwaighte JB, Liebovitch LS, West BJ (1994) Fractal Physiology, New York: Oxford University Press

Bauer H, Thoni W (1988) Photosynthetic light acclimation in fully developed leaves of the juvenile and adult life phases of Hedera helix. Physiologia Plantarum 73: 31-37

Boyce CK, Brodribb TJ, Feild TS, Zwieniecki MA (2009) Angiosperm leaf vein evolution was physiologically and environmentally transformative. Proceedings of the Royal Society B: Biological Sciences 276: 17711776

Brodribb TJ, Feild TS (2010) Leaf hydraulic evolution led a surge in leaf photosynthetic capacity during early angiosperm diversification. Ecology Letters 13: 175-183

Candela H, Martinez-Laborda A, Micol JL (1999) Venation pattern formation in Arabidopsis thaliana vegetative leaves. Developmental Biology 205: 205-216

Chen X, Yang G, Song JH, Xu H, Li D, Goldsmith J, Zeng H, Parsons-Wingerter PA, Reinecker HC, Kelly CP (2013) Probiotic yeast inhibits VEGFR signaling and 


\section{VESGEN Mapping of Leaf Venation Patterns in Arabidopsis}

angiogenesis in intestinal inflammation. PLoS One 8: e64227

Chua YL, Channeliere S, Mott E, Gray JC (2005) The bromodomain protein GTE6 controls leaf development in Arabidopsis by histone acetylation at ASYMMETRIC LEAVES1. Genes \& Development 19: 2245-2254

Clarke JH, Tack D, Findlay K, Van Montagu M, Van Lijsebettens M (1999) The SERRATE locus controls the formation of the early juvenile leaves and phase length in Arabidopsis. The Plant Journal 20: 493-501

Clay NK, Nelson T (2005) Arabidopsis thickvein mutation affects vein thickness and organ vascularization, and resides in a provascular cell-specific spermine synthase involved in vein definition and in polar auxin transport. Plant Physiology 138: 767-777

Crepet WL, Niklas KJ (2009) Darwin's second "abominable mystery": Why are there so many angiosperm species? American Journal of Botany 96: 366-381

de Boer HJ, Eppinga MB, Wassen MJ, Dekker SC (2012) A critical transition in leaf evolution facilitated the Cretaceous angiosperm revolution. Nature Communications 3: article number: 1221

Delker C, Raschke A, Quint M (2008) Auxin dynamics: the dazzling complexity of a small molecule's message. Planta 227: 929-941

Dhondt S, Van Haerenborgh D, Van Cauwenbergh C, Merks RM, Philips W, Beemster GT, Inze D (2012) Quantitative analysis of venation patterns of Arabidopsis leaves by supervised image analysis. The Plant Journal : for Cell and Molecular Biology 69: 553-563

Ellis B, Daly DC, Hickey LJ, Kirk RJ, Mitchell JD, Wilf P, Wing SL (2009) Manual of Leaf Architecture, Ithaca, NY: Cornell University Press

Esau K (1965) Plant Anatomy, Second edn, New York: John Wiley and Sons, Inc

Ferl R, Wheeler R, Levine HG, Paul A-L (2002) Plants in space. Current Opinion in Plant Biology 5: 258-263

Ferl RJ, Zupanska A, Spinale A, Reed D, Manning-Roach S, Guerra G, Cox DR, Paul A-L (2011) The performance of KSC Fixation Tubes with RNALater for orbital experiments: A case study in ISS operations for molecular biology. Advances in Space Research 48: 199-206

Guyton AC, Hall JE (2006) Textbook of Medical Physiology, 11th edn, Philadelphia: Elsevier Saunders

Hickey LJ (1973) Classification of the architecture of dicotyledeonous leaves. American Journal of Botany 60: 17-33

Hickey LJ (1979) A revised classification of the architecture of dicotyledonous leaves. In Anatomy of the Dicotyledons, C.R. Metcalfe, L. Chalk (eds), Second edn, pp 25-39. Oxford: Clarendon Press

Horowitz A, Simons M (2009) Branching morphogenesis. Circulation Research 104: e21

Huijser P, Schmid M (2011) The control of developmental phase transitions in plants. Development 138: 4117-4129

Kang J, Dengler N (2004) Vein pattern development in adult leaves of Arabidopsis thaliana. International Journal of Plant Science 165: 231-242

Kang J, Mizukami Y, Wang H, Fowke L, Dengler NG (2007) Modification of cell proliferation patterns alters leaf vein architecture in Arabidopsis thaliana. Planta 226: 1207-1218

Kankel MW, Ramsey DE, Stokes TL, Flowers SK, Haag JR, Jeddeloh JA, Riddle NC, Verbsky ML, Richards EJ (2003) Arabidopsis MET1 cytosine methyltransferase mutants. Genetics 163: 1109-1122

Lamont RE, Childs S (2006) MAPping out arteries and veins. Science STKE 2006: pe39

Levine HG (2010) The influence of microgravity on plants. In NASA ISS Research and PreApplication Meeting, League City, TX, August 3-5. Retrieved from http://www.nasa. gov/pdf/478076main_Day1_P03c_Levine_Pla nts.pdf

Liu H, Yang Q, Radhakrishnan K, Whitfield DE, Everhart CL, Parsons-Wingerter P, Fisher SA (2009) Role of VEGF and tissue hypoxia in patterning of neural and vascular cells recruited to the embryonic heart. Developmental Dynamics 238: 2760-2769

Lobet G (2013-2014) Plant Image Analysis. University of Liege and others (ed) Retrieved from http://www.plant-image-analysis.org/

Mandelbrot BB (1983) The Fractal Geometry of Nature, San Francisco: W. H. Freeman 


\section{VESGEN Mapping of Leaf Venation Patterns in Arabidopsis}

McKay TL, Gedeon DJ, Vickerman MB, Hylton AG, Ribita D, Olar HH, Kaiser PK, ParsonsWingerter P (2008) Selective inhibition of angiogenesis in small blood vessels and decrease in vessel diameter throughout the vascular tree by triamcinolone acetonide. Investigative Ophthalmology \& Visual Science 49: 1184-1190

Monje O, Goins GD, Tripathy BC, Stutte GW (2005) Microgravity effects on thylakoid, single leaf, and whole canopy photosynthesis on dwarf wheat. Planta 223: 46-56

Monje O, Hatfield RD, Stutte GW, Paul A-L, Ferl RJ, Simone CG (2006) Microgravity effects on leaf morphology, cell structure, carbon metabolism and mRNA expression of dwarf wheat. Planta 224: 1038-1049

Muller B, Grossniklaus U (2010) Model organisms - a historical perspective. Journal of Proteomics 73: 2054-2063

Musgrave ME (2007) Growing plants in space. $C A B$ Reviews: Perspectives in Agriculture, Veterinary Science, Nutrition and Natural Resources 2: 9

Nicotra AB, Leigh A, Boyce CK, Niklas KJ, Royer DL, Tsukaya H (2011) The evolution and functional significance of leaf shape in the angiosperms. Functional Plant Biology 38: $535-552$

Page DR, Grossniklaus U (2002) The art and design of genetic screens: Arabidopsis thaliana. Nature Review Genetics 3: 124-136

Parsons-Wingerter P, Chandrasekharan UM, McKay TL, Radhakrishnan K, DiCorleto PE, Albarran B, Farr AG (2006a) A VEGF165induced phenotypic switch from increased vessel density to increased vessel diameter and increased endothelial NOS activity. Microvascular Research 72: 91-100

Parsons-Wingerter P, Elliott KE, Clark JI, Farr AG (2000a) Fibroblast growth factor-2 selectively stimulates angiogenesis of small vessels in arterial tree. Arteriosclerosis, Thrombosis, and Vascular Biology 20: 12501256

Parsons-Wingerter P, Elliott KE, Farr AG, Radhakrishnan K, Clark JI, Sage EH (2000b) Generational analysis reveals that TGF-beta1 inhibits the rate of angiogenesis in vivo by selective decrease in the number of new vessels. Microvascular Research 59: 221-232
Parsons-Wingerter P, Lwai B, Yang MC, Elliott KE, Milaninia A, Redlitz A, Clark JI, Sage EH (1998) A novel assay of angiogenesis in the quail chorioallantoic membrane: stimulation by bFGF and inhibition by angiostatin according to fractal dimension and grid intersection. Microvascualr Research 55: 201-214

Parsons-Wingerter P, McKay TL, Leontiev D, Vickerman MB, Condrich TK, Dicorleto PE (2006b) Lymphangiogenesis by blind-ended vessel sprouting is concurrent with hemangiogenesis by vascular splitting. The Anatomical Record Part A 288: 233-247

Parsons-Wingerter P, Radhakrishnan K, Vickerman M, Kaiser P (2010) Oscillation of angiogenesis with vascular dropout in diabetic retinopathy by VESsel GENeration analysis (VESGEN). Investigative Ophthalmology \& Visual Science 51: 498-507

Parsons-Wingerter P, Reinecker H-C (2012) For application to human spaceflight and ISS experiments: VESGEN mapping of microvascular network remodeling during intestinal inflammation. Gravitational and Space Biology 26: 2-12

Parsons-Wingerter P, Vickerman MB (2011) Informative mapping by VESGEN analysis of venation branching pattern in plant leaves such as Arabidopsis thaliana. Gravitational and Space Biology 25: 69-71

Paul A-L, Daugherty CJ, Bihn EA, Chapman DK, Norwood KL, Ferl RJ (2001) Transgene expression patterns indicate that spaceflight affects stress signal perception and transduction in Arabidopsis. Plant Physiology 126: $613-621$

Paul A-L, Wheeler RM, Levine HG, Ferl RJ (2013a) Fundamental plant biology enabled by the space shuttle. American Journal of Botonay 100: 226-234

Paul A-L, Zupanska AK, Ostrow DT, Zhang Y, Sun Y, Li JL, Shanker S, Farmerie WG, Amalfitano CE, Ferl RJ (2012) Spaceflight transcriptomes: unique responses to a novel environment. Astrobiology 12: 40-56

Paul A-L, Zupanska AK, Schultz ER, Ferl RJ (2013b) Organ-specific remodeling of the Arabidopsis transcriptome in response to spaceflight. BMC Plant Biology 13: 112 
Pennisi E (2010) On rarity and richness. Science 327: $1318-1319$

Poethig RS (1990) Phase change and the regulation of shoot morphogenesis in plants. Science 250: 923-930

Price CA, Symonova O, Y. M, T. H, Weitz JS (2011) Leaf extraction and analysis famework graphical user interface: segmenting and analyzing the structure of leaf veins and areoles. Plant Physiology 155: 236-245

Pulido A, Laufs P (2010) Co-ordination of developmental processes by small RNAs during leaf development. Journal of Experimental Botany 61: 1277-1291

Rolland-Lagan AG, Amin M, Pakulska M (2009) Quantifying leaf venation patterns: twodimensional maps. The Plant Journal : for Cell and Molecular Biology 57: 195-205

Roth-Nebelsick A, Uhl D, Mosbrugger V, Kerp H (2001) Evolution and function of leaf venation architecture: a review. Annals of Botany 87: 553-566

Scarpella E, Helariutta Y (2010) Vascular pattern formation in plants. In Plant Development, M.C.P. Timmerman (ed), 8, pp 221-266. San Diego: Academic Press

Sicker RJ, Meyer WV (2013) Light Microscopy Module (LMM). Space Flight Systems @ GRC, Physical Science Research Program. Retreived from http://spaceflight systems. grc.nasa.gov/SOPO/ICHO/IRP/FCF/Investiga tions/LMM/LMM_Brochure/index.php in http://spaceflightsystems.grc.nasa.gov/ $\mathrm{SOPO} / \mathrm{ICHO} / \mathrm{IRP} / \mathrm{FCF} /$ Investigations/LMM/

Sturm JG (1796) Deutschlands Flora in Abbildungen. Retrieved from http://www. biolib.de/ and http://commons. wikimedia.org /wiki/File\%3AArabis_thaliana_Sturm6.jpg

Taiz L, Zeiger E (2010) Plant Physiology, 5th edn. Sunderland MA: Sinauer Associates, Inc

Telfer A, Bollman KM, Poethig RS (1997) Phase change and the regulation of trichome distribution in Arabidopsis thaliana. Development 124: 645-654
Tripathy BC, Brown CS, Levine HG, Krikorian AD (1996) Growth and photosynthetic responses of wheat plants grown in space. Plant Physiology 110: 801-806

Turner S, Sieburth LE (2003) Vascular patterning. The Arabidopsis Book 2: $\mathrm{e} 0073$

Velikova V, Loreto F, Brilli F, Stefanov D, Yordanov I (2008) Characterization of juvenile and adult leaves of Eucalyptus globulus showing distinct heteroblastic development: photosynthesis and volatile isoprenoids. Plant Biology (Stuttg) 10: 55-64

Vickerman MB, Keith PA, McKay TL, Gedeon DJ, Watanabe M, Montano M, Karunamuni G, Kaiser PK, Sears JE, Ebrahem Q, Ribita D, Hylton AG, Parsons-Wingerter P (2009) VESGEN 2D: automated, user-interactive software for quantification and mapping of angiogenic and lymphangiogenic trees and networks. The Anatomical Record Part A 292: 320-332

Vogel S (2012) The Life of a Leaf, Chicago and London: The University of Chicago Press

Willmann MR, Poethig RS (2011) The effect of the floral repressor FLC on the timing and progression of vegetative phase change in Arabidopsis. Development 138: 677-685

WISTEP (2014). Retrieved from http://biology. wisc.edu/K12-ProfessionalDevelopmentfor K12Educators-WisTEP.htm

Wolverton C, Kiss JZ (2009) An update on plant space biology. Gravitational and Space Biology 22: 13-20

Wu G, Park MY, Conway SR, Wang JW, Weigel D, Poethig RS (2009) The sequential action of miR156 and miR172 regulates developmental timing in Arabidopsis. Cell 138: 750-759

Zamanian-Daryoush M, Lindner D, Tallant TC, Wang Z, Buffa J, Klipfell E, Parker Y, Hatala $\mathrm{D}$, Parsons-Wingerter P, Rayman P, Yusufishaq MS, Fisher EA, Smith JD, Finke J, Didonato JA, Hazen SL (2013) The cardioprotective protein ApoA1 promotes potent anti-tumorigenic effects. Journal of Biological Chemistry 288: 21237-21252 